\title{
Function Modeling in Engineering Design: Approaches and Methods
}

\author{
Osamah Malik Mohammed, Ahmed Z.M. Shammari \\ Mech. Eng. Dept. / College of Engineering, Al-Khwarizmi College of Engineering \\ University of Baghdad \\ Baghdad, Iraq \\ osamadirweesh@hotmail.com \\ osamadirweesh@uobaghdad.edu.iq
}

\begin{abstract}
Function modeling in engineering design, as one of the most common abstract language during design process and especially early stages, is introduced in a common frame for investigating possible development areas. Comparative studies are conducted for analysing commonalities of various approaches and methods as well as its variances. The interaction of functional modeling with design theories and methodologies are reviewed in detail. The aims of those reviews are highlighting features of various methods of FM and its noticed limitations and discussing applicability of those methods and approaches in various fields of design. Finally, a proposed future works is presented for filling identified gaps within generality and applicability of FM within various design fields.
\end{abstract}

Keywords. Function Modeling; Functional Design; Engineering Design; Function Representation; Functional Decomposition; Design-based Function.

\section{Introduction}

Function modeling (FM) is an expression for high level representation of products and processes according to their functionalities. The intrinsic purpose of function modeling is how to represent design knowledge in function terms for its importance as a general and communication framework, also, to facilitate functional reasoning in automated systems.

FM provides a strong basis for solving problems within representation of complex products and systems as well as their related complex processes. This complexity arises from the idea that most of developed products and systems in our time are multidisciplinary, in which, a single designer or even design team cannot handle all disciplines of intended products and systems with their processes (Szykman, Sriram, et al., 1999). For overcoming barriers among multiple disciplines, FM provides a general high-level abstract language depending on its functionality. In the same, FM decomposition fills the gap between high-level requirements and the rest of low-level component and structure details through providing a holistic view for the whole system and its related processes (Pahl, Beitz, Feldhusen, \& Grote, 2007). 


\section{Historical analysis of function modeling}

The importance and usefulness of functional modeling in engineering design process had been implied and advocated in numerous engineering design texts (Hundal, 1990; Cutherell, 1996; Otto and Wood, 2001; Barry Hyman, 2003; Pahl et al., 2007; Ulrich and Eppinger, 2012). Development of functional modeling methods launched with verb-noun pairs style for describing value analysis functionality by Miles (Lawrence D. Miles, 1961), where, he developed a representation schema considering that main usefulness of every product and system comes from its functionality (Lawrence D. Miles, 1961). While, transformation models of energy, material, and information as Input/Output flows had been initiated by Rodenacker for functionality description of products and first trials as defining functions in conceptual design (Rodenacker \& Schäfer, 1978).

Roth used Rodenacker's work for basic function definitions in engineering design (Roth, 1982). Koller presented a first shot for the use of 12 basic functions (Koller, 1985), while Hundal suggested set of functions as well as flow classes (without specifying flow information) (Hundal, 1990).

During 1997, Flow's information had been included in a functional basis set by Little et al. (Little, Wood, \& McAdams, 1997). Standardization process for functions and flows vocabulary sets began by Szykman (Szykman, Racz, \& Sriram, 1999), while Stone (Stone \& Wood, 2000) developed Szykman's vocabulary with different structure and a modified term.

Hirtz et al. reconciled previous works for building the known Reconciled Functional Basis (RFB), that had been used as a basic library in functional design for multiple universities and institutes as well as practiced designers (Hirtz, Stone, McAdams, Szykman, \& Wood, 2002). The last, sometimes called as Functional Basis (FB), and because of the former is called with the same term, RFB term will be considered in this dissertation.

Also, in parallel, there are numerous techniques in functional modeling presented for aiding product's engineering design. In 1996, a novel Function-Behavior-State (FBS) modeling technique is interconnecting functions (as intent of designer) with behavior as function's realization (Umeda, Ishii, Yoshioka, Shimomura, \& Tomiyama, 1996). While, in 1998, Function-Evolution-Process (FEP) had been built upon previously mentioned Umeda's FBS through functional model evolution with design concluding "not merely the structure design, but also the intended functions as results of design" (Shimomura, Yoshioka, Takeda, Umeda, \& Tomiyama, 1998). Gero's well-known framework of Function-Behavior-Structure illustrated various domains of conceptual design process as variable classes striving for capturing the internal transformations among these three domains (Gero, 1990a).

After more than a decade, during 2004, Gero's FBS is extended to situated-Function-BehaviorStructure ( $F F B S$ ) through including dynamic context utilizing environmental interactions (Gero \& Kannengiesser, 2004). Separately, in 2002, The Behavior-driven Function-Environment-Structure (B$F E S$ ) proposed mapping function-behavior-physical structure, where, behavior acts as more detailed high-level functionality (W. Y. Y. Zhang, Tor, Britton, \& Deng, 2002). In the same previous year 2000, Function-means trees elucidated function's codependence that can be fulfilled with means, where, it had been hierarchically arranged for building tree structure demonstrating alternative function means for multiple design solutions (Robotham, 2002). After that, during 2001, Integrated Definition Method \#0 (IDEF0) introduced a functional modeling framework for identifying elements (people, information, materials...etc) for an operation performance (Lo, Humphreys, \& Sculli, 2001).

\subsection{Functional Ontology}

(Kitamura \& Mizoguchi, 2004) states "functional models represent a part of (but not all of) intention of designer, or whats called rationale of design." Other similar methods that are not FM oriented and implicitly used in other applications such as FMEA (Klein \& Lalli, 1989; Rausand \& Oien, 1996) and FTA (Lee, Grosh, Tillman, \& Lie, 1985). Nevertheless, those methods are task specific (Kitamura \& Mizoguchi, 2004). In contrary, FM requires more generality for supporting ease of description as well retrieval of knowledge in various domains. Functional ontology explicit any framework providing 
necessary vocabulary and viewpoints for representing functional knowledge (Kitamura, Kashiwase, Fuse, \& Mizoguchi, 2004; Kitamura \& Mizoguchi, 2003, 2004).

There are three distinguished domain ontologies for modelling and describing engineering systems and products (Erden et al., 2008): Device Ontology, Process Ontology, and Functional Concept Ontology.

Device Ontology suppose that a system is composed of black box modules as agents that are connected each other with Input/Output associations such as qualitative physics of (De Kleer \& Brown, 1984) and Systematic Approach of (Pahl et al., 2007) as well it's the most common ontology among others.

Process Ontology is used less than other ontologies and there are no agents within it as it focuses on processes, where entities are changing as consequences resulting from process effects (Kitamura \& Mizoguchi, 2004). For instance, the QPT (Qualitative Process Theory) proposed by (Forbus, 1984) that is considered as a pioneer of this ontology type.

FCO (Functional Concept Ontology) considering to develop a system from a teleological viewpoint, where the FM model is based on questions of what the system as well its components is supposed to do and whats the purpose of it. FCO is intended for developing functionality framework and language depending on human's subjective viewpoint, and there are many examples of this type such as works of (Chandrasekaran \& Josephson, 2000; Keuneke, 1991; Umeda et al., 1996; Umeda \& Tomiyama, 1995; Yoshioka et al., 2004).

(Umeda \& Tomiyama, 1995) regarded function as a bridge that connects physical behavior of artifacts with human intention. Also, the authors stated that it is not possible to define function objectively. Many other researchers acknowledged the subjectivity of function and its being an transitional process between human intentions and objects such as (Balachandran \& Gero, 1990; Chandrasekaran \& Josephson, 2000; Y. M. Deng, Tor, \& Britton, 2000; Keuneke, 1991). Nevertheless, other conceptions in previous literature does not consider subjectivity of function, in which it considers direct match between function and its associated physical artefact. (Rodenacker, 1971) identified function as an association between input and output (energy, material, and information), where, this definition is broadly acknowledged in design research (Pahl et al., 2007; Welch \& Dixon, 1992). (Bracewell \& Sharpe, 1996) extended function representation based on bond graph theory, and (Rosenberg \& Karnopp, 1983) presented concept of "flow" as well "effort to cause a flow" as first time to be presented. (Lawrence D. Miles, 1961) in his value engineering method represented function as "to do something". All previous definitions and representations share the viewpoint of subjectivity of function.

\subsection{Functional Representation}

Functional representation is termed for defining function-associated entities, attributes and their associations (Ahmed \& Wallace, 2003). Two viewpoints of function are identified by (Chandrasekaran \& Josephson, 2000): environment-centric and device-centric viewpoints. Where, environment-centric defines function as the on environment by an object, where, many models are adopting this definition, such as Function-Behavior-State (FBS) (Gero, 1990b), Function-Environment-Behavior-Structure (FEBS) (Y. M. Deng, 2002), (Yi Min Deng, Britton, \& Tor, 2000), (Yi Min Deng, Tor, \& Britton, 1999), and (Tor, Deng, \& Britton, 1999).

While, device-centric is regarded for most of other works as it focusses on internal parameters and features of the object. (Borgo, Carrara, Garbacz, \& Vermaas, 2009) considered that DOLCE can capture the two viewpoints through concepts of behavioral constraints and deployment mode of an artifact. Vocabulary for describing associated domains and entities (function ontology) as well its organization and internal relations for functional knowledge representation that mostly regarded together.

Roughly, functional ontology is classified into three kinds: device - based, process - based, and FCO (Functional Concept Ontology). Several researchers adopted device-based and FCO (Ahmed \& 
Wallace, 2003; De Kleer \& Brown, 1984; Y. M. Deng, 2002; Keuneke, 1991; Kitamura \& Mizoguchi, 2004; Komoto \& Tomiyama, 2011; Pahl et al., 2007; Umeda et al., 1996; Yoshioka et al., 2004). Other few researchers adopted process-based such as (Forbus, 1984).

(De Kleer \& Brown, 1984) was the pioneer of device-based ontology that considered a set of black boxes forming a device or system that are connected each other with input/ output relations. (Pahl et al., 2007) proposed the well-known Systematic Approach, in which adopting device-based ontology. (Kitamura \& Mizoguchi, 2003, 2004) presented their approaches based on their device-based ontology. Also, (Stone \& Wood, 2000) in their Functional Basis provided standard taxonomy for function representation that is based on separated similar Functional Basis developed by (Szykman, Racz, et al., 1999), the previous two functional bases are reconciled by (Hirtz et al., 2002) as the most common standard taxonomy for function representation under supervision and participation of NIST.

(Pailhès, Sallaou, Nadeau, \& Fadel, 2011) introduced functional relations depending on simplifying all flow types into energy flows. The works of (Russo \& Montecchi, 2011b, 2011a) in some extent is device-based, where they used KOM (Knowledge Organizing Module) for constructing FBP (FunctionBehavior-Physical effect) tree.

As the same, (Chakrabarti, 2009) developed SAPPhIRE model for function representation that consists of seven concepts (State Change, Action, Part, Phenomenon, Input, Organ, and Effect) organized for explaining causality of engineered and natural systems, in which implemented as a software system called IDEA-INSPIRE that provides analogical search support for designer and the function is represented as verb, noun, and adjective (behavioral language).

(Yi Min Deng et al., 1999) represented function as Input/Output variables directly and referred as device-based. (Keuneke, 1991) also is considered as device-based ontology, where four function types are identified: ToMake, ToMaintain, ToPrevent, and ToControl. However, object identification is unclear in her ontology and no specific criterion for which role that must be played and by which component as well the implicit assumptions behind her ontology. (Kitamura \& Mizoguchi, 2004) stated that modelling of artefacts based on (Keuneke, 1991) ontology is considered as ad hoc.

FCO aiming to develop a device/system model depending on teleological point of view, where it tries developing functionality model language for a system upon subjective view of humans. (Umeda et al., 1996) regards that function is bridging physical behavior of artefacts with human intention as proposed within their Function-Behavior-State (FBState) model for representing associated information. The previous is similar to known approach FBS of (Gero, 1990a) that is also device-based. Both of previous FBSs models are adopted by (Cascini, Russo, \& Zini, 2007) and (Fantoni, Apreda, Dell'Orletta, \& Monge, 2013) for extracting function related information from existing patents. Many other researchers recognized subjective character of functions such as (Brown, 2003; Chandrasekaran \& Josephson, 2000; Kitamura \& Mizoguchi, 2003; Umeda et al., 1996; Yoshioka et al., 2004).

\subsection{Functional Decomposition}

Several attempts for developing functional decomposition methods and automating it. (Umeda, Takeda, Tomiyama, \& Yoshikawa, 1990) developed FBS modeller as a functional decomposition tool. (Umeda \& Tomiyama, 1995) depended hierarchical functional decomposition as a basic task in engineering design, where, the researchers discussed that hierarchical functional decomposition is only in subjective not objective realm, as (Umeda et al., 1990) assured that there is not algorithm for functional decomposition and this process continue manually until it decomposed subfunctions relate to some physical artefact. Despite of, many attempts are conducted during last two decades as will be detailed.

In FBS modeller, decomposition process is divided into task and causal decomposition, in which, knowledge of decomposition is stored in KB (Umeda et al., 1996). Task decomposition is conducted manually as a mental activity, while causal decomposition resulted in causally related subfunctions. Therefore, it recommends knowledge of physical behavior. FBS modeller provides a subsystem called QPA (qualitative process abduction) for supporting causal decomposition during engineering design. 
KRITIK system developed by (Goel, 1989, 1992; Goel, Bhatta, \& Stroulia, 1997) utilizes SBF modeling, where, behaviors are represented at several levels of abstraction and aggregation hierarchically, functions and behaviors are decomposed concurrently in relative to each other. The representation has the schema of $\mathrm{F} \rightarrow \mathrm{B} \rightarrow \mathrm{F} \rightarrow \mathrm{B} \rightarrow \ldots \rightarrow \mathrm{F}(\mathrm{s})$, in which, higher level function is realized with some behaviors and higher-level behaviors are related with lower lever functions until the last associate with concrete component. In this schema, the function (Goel \& Bhatta, 2004) is considered as an index for of causal behavior in charge of its realization.

SchemeBuilder (Bracewell \& Sharpe, 1996) is a knowledge based design environment system depending on bond graph that generates alternative solutions of schemes as function-means tree structure utilizing some decomposition principles inherited from bond graph ontology, as the last is considered as a formal representation of physical systems for linking energy flows within processes in a system. Where, only compatible ports of energy flows can connect to each other. In the same, physical systems in SchemeBuilder are classified functionally.

Step-by-step decomposition process is performed for required functions and subfunctions corresponding for associating it with components (means) or a one or more required functions (working principle).

(Welch \& Dixon, 1994) developed primitives of behavior (features) for conceptual design of mechanical systems as it generates behavior graphs based on combinations of primitives available in KB.

(Snooke \& Price, 1998) presented functional label idea for associating system components with behaviors hierarchically at several levels of abstraction, where, its applied for designing and diagnosing electrical systems of automotive.

(Y. M. Deng, 2002) defined rules for construction of mapping model for function decomposition as it syntactically supports developing function model.

(Kitamura \& Mizoguchi, 2003) proposed a knowledge based system for function decomposition called "Function-Way-Server" for supporting designers, which it explores different decompositions that achieve the goal. (Kitamura \& Mizoguchi, 2004) defined functionalities based on three ontological relations "is-a, a part of, and is achieved by". "is-a for function abstraction," "a part of for function composition" and "is achieved by for association between function and its structure as well its behavior".

(Kitamura et al., 2004) built SOFAST system for description and sharing functional knowledge in an intranetworking. The authors stated that it had been actively used by three companies and provided to thirteen other companies, where, it yet working as storage system not as intelligent design support system.

\section{Relation of FM with Different Research Fields}

The main usage of FM is engineering design process of multidisciplinary systems and its maintenance (Erden et al., 2008). In engineering design process, FM is employed for understanding an existent design for redesign purposes and future development as well for design new multidisciplinary systems, where the last requires reasoning with computers that mostly inhabits adopting artificial intelligence techniques. Therefore, there are an important association between FM and AI. In fact, design research with FM is an emergent outstanding field for supporting engineering design process as a whole and conceptual design phase in specific.

Also, FM can be benefited throughout product life cycle such as maintenance, diagnosis, and failure detection. Where, one of its benefits over structural analysis, FM can give results within conceptual design phase. In the following subsections, the relation of FM and AI, and design theory will be discussed. 


\subsection{FM and AI}

AI techniques are intended for mimicking intelligent human activities starting from modelling and reasoning going through planning and diagnosis as well qualitative simulation during product development associated activities such as engineering design process.

FR system can be utilized through product development for planning and design purposes as verification and design improvement as well new designs in conceptual design phase. Also, it can be used for explanations as in fault diagnosis and failure modes.

Functional reasoning (FR) relates FM with AI technologies (Chandrasekaran, 1994a, 1994b). According to (Far \& Elamy, 2006), FR scheme includes three basics, "Ontology", "Representation", and relative "Relations". Where, Ontology is describing domain and entities, while Representation for modelling referred entities and Relations for relating it.

Several AI techniques are used within FR such as heuristic search, explorations and exploitation, pattern matching, and clustering as considered as a first-generation FR system that are restricted to direct match inferencing (Far \& Elamy, 2006). There are several correspondences among functional, behavioral, and physical structure descriptions, where, mapping process from function to behavior and behavior to structure are considered as complex combinatorial problem that requires a suitable reasoning strategy. (Far \& Elamy, 2006) considered that combining Model-Based Reasoning (MBR) technologies with FM as the second-generation FR system that is useful for suitable reasoning mechanisms. Those systems can be utilized for simulation purposes as it involves functionalities for diagnosis and FA (failure analysis). Four independent tasks that FR can be applied: Identification, Explanation, Selection, and Verification (Far \& Elamy, 2006).

FM performance within AI realm largely depends on modelling approach as modelling depends function representation in its association with behavior, structure, etc. Also, function definition is very important as it effects directly on precision of functional representation and its utilization within AI techniques (Chandrasekaran, 2005).

\subsection{FM and Design Theory}

For managing multidisciplinary nature and increasing complexity of engineering design process, FM can utilized effectively. (America \& van Wijgerden, 2000) employed requirements modelling usage within real industrial case study. (Maarten Bonnema \& van Houten, 2006) investigated usage of models at conceptual phase of engineering design for handling large amounts of data to be benefited for communication and problem analysis purposes.

(Yoshioka et al., 2004) illustrate that functional models provide a structure for the design process and ease the handling of large amounts of data. In the following subsection a discussion of the two classical design methodologies that are in relation to FM is given. Then two design methodologies that are explicitly FM oriented are reviewed. Finally, some emergent CAD tools are introduced. These are implementations of the FM paradigms of their developers with some reasoning processes.

\section{Applications of FM in Ongoing Research}

In this section an introduction of the ongoing research in the Intelligent Mechanical Systems Group is given. The work reported is inspired by and makes use of the ideas developed within the FM framework. The basic issues of the projects, such as evolvability, unpredicted interferences, intelligent maintenance, and service modeling, are explained in the context of the FM. The abstract of this work is clarified and detailed within Table 1, Table 2, and Table 3.

\section{Conclusions}

In this review, FM approaches and methods are explored for initiating general framework for functional modelling from perspectives of ontologies, representations, decomposition, and other related application fields within engineering design. Subjective and objective realms of FM are 
separated considering functions as subjective linkage between the two realms through subjective recognition of some objective behaviours.

A discussion of fundamentals and principles of FM terms are performed through surveying function ontology, functional representations, functional decomposition, various function definitions, as well other related FM fields within engineering design. Multiple comparisons of various approaches areconducted tabularly for revealing mainline trends of current issues.

Several FM approaches and methods are present, that are not compatible with each other. The variety of FM approaches and methods resulting from various disciplines of FM applications brought up a good question of providing a general FM framework.

FBS family of functional representations are explored and recognized with benefited tabular comparison for identifying its commonalities and variations. The application of AI within FM approaches is considered as it can be a large gate through which FM can cross over current research borders to practicality of its applications.

Function reasoning is surveyed through exploring concrete CAD tools and FM systems as well its benefit and effects on design process.

This review revealed fundamental advantages such as the necessity of integration between high level representation of systems with its lower levels, as well the interactions of various disciplines of engineering domains as it represents a crucial task in engineering design of multidisciplinary systems. Other main advantage is providing a general FM framework for computer reasoning in many states such as functional representation and functional decomposition as well functional reasoning. 


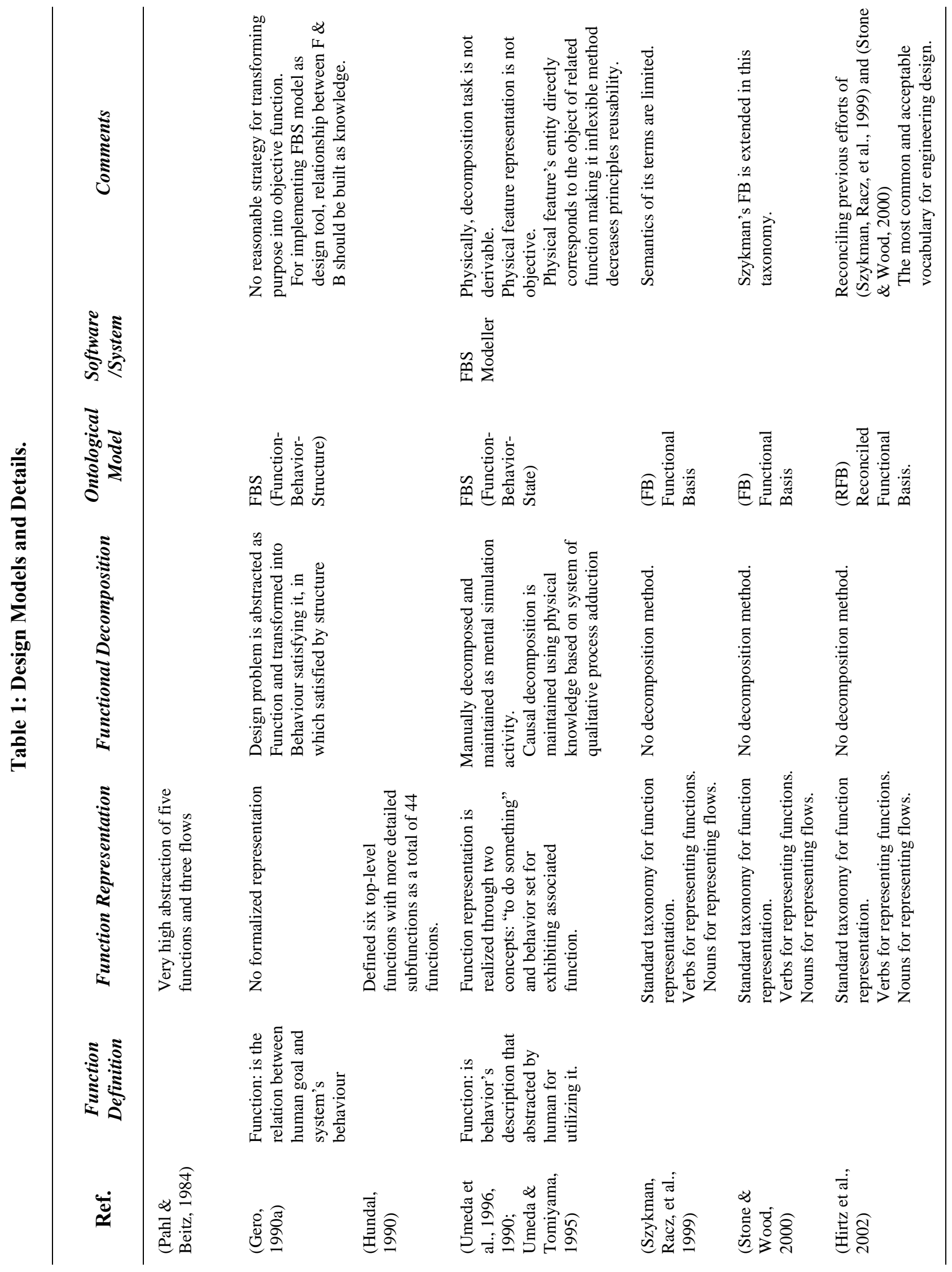




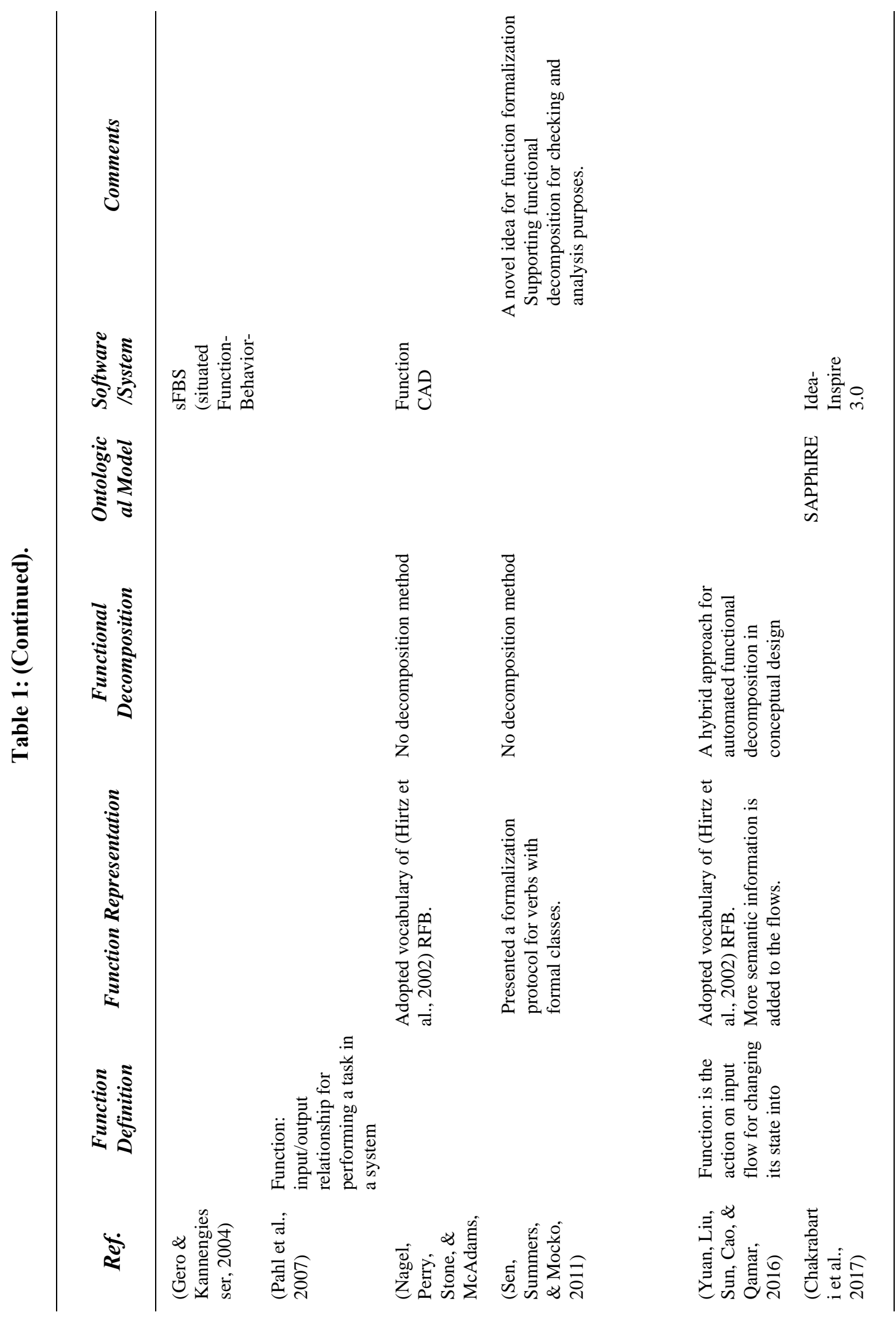




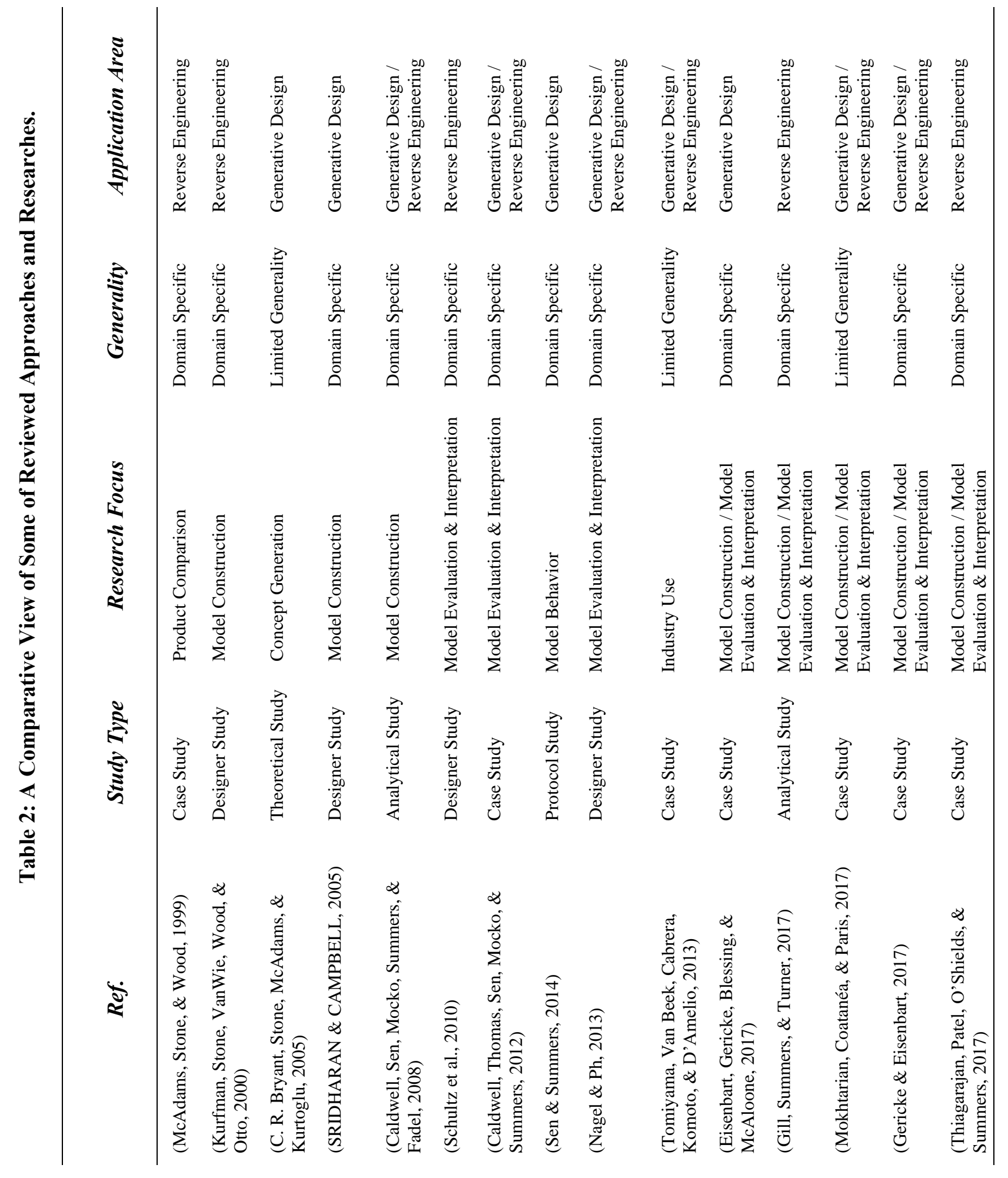




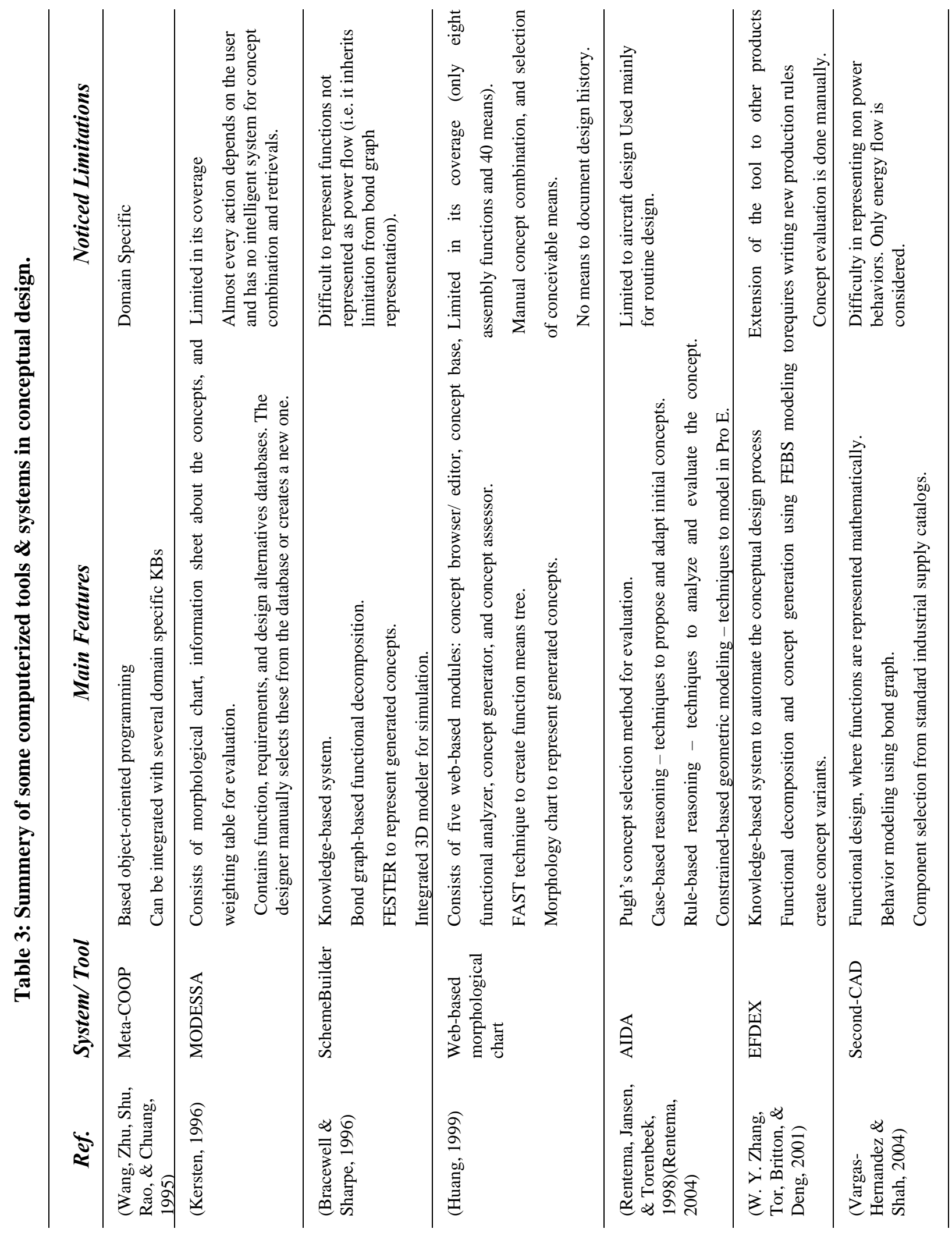




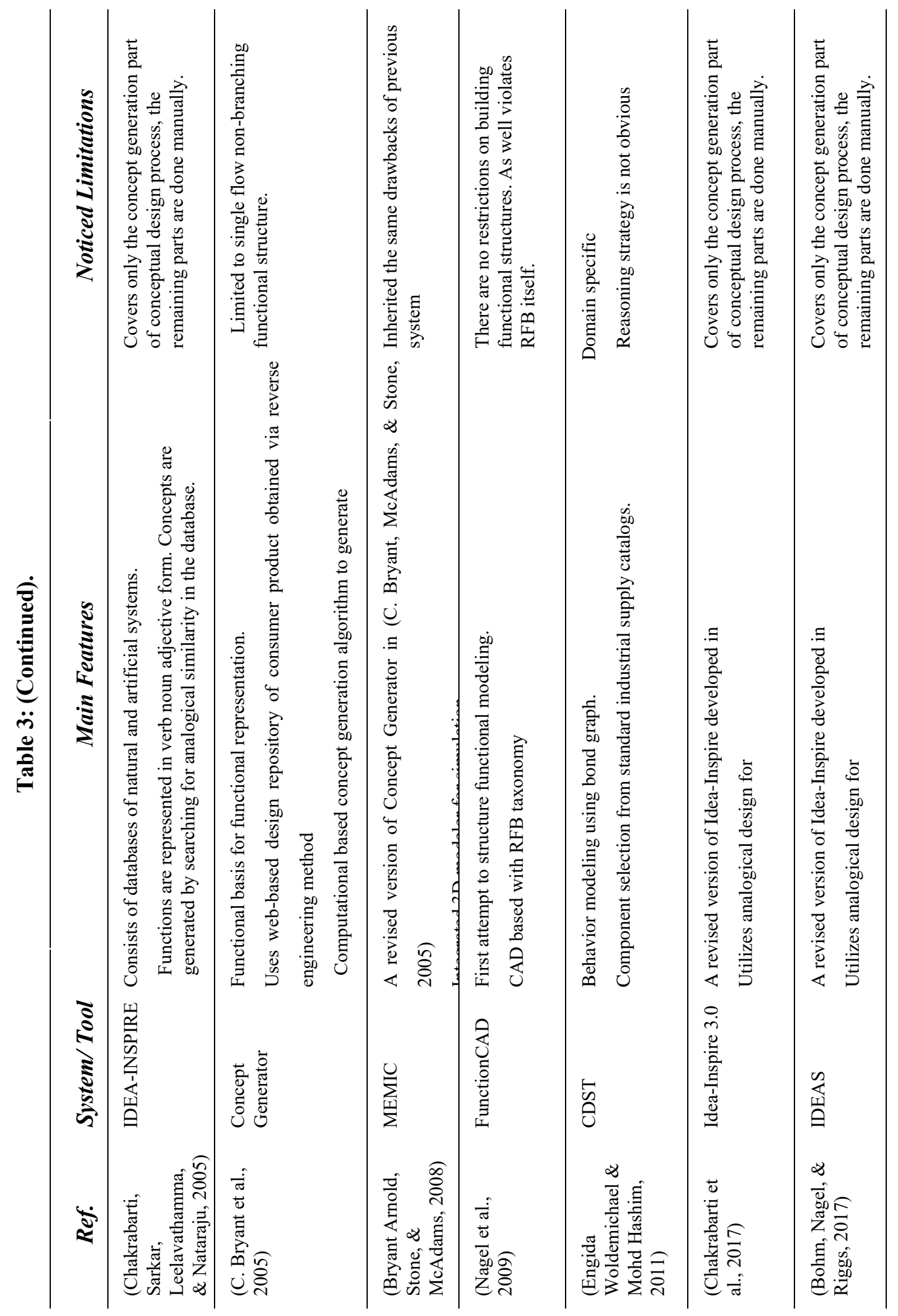




\section{References}

[1] S. Szykman, R. D. Sriram, T. Khanh, H. Jean-Francois, A. Cuilhem, and A. Sylvain, "The NIST Design Repository Project: Project Overview and Implementational Design," Adv. Soft Comput., pp. 5-19, 1999.

[2] G. Pahl, W. Beitz, J. Feldhusen, and K.-H. Grote, Engineering Design. London: Springer London, 2007.

[3] Lawrence D. Miles, Techniques of value analysis and engineering. New York, USA: McGrawHill, 1961.

[4] M. . Hundal, "A Systematic method for developing function structures, solutions and concept variants," Mech. Mach. Theory, vol. 25, no. 3, pp. 243-256, Jan. 1990.

[5] K. T. Ulrich and S. D. Eppinger, Product Design and Development: Fifth Edition. 2012.

[6] K. N. Otto and K. L. Wood, Product Design: Techniques in Reverse Engineering and New Product Development. Prentice Hall, 2001.

[7] Barry Hyman, Fundamentals of Engineering Design, 2nd Editio. Pearson Higher Ed USA, 2003.

[8] D. Cutherell, "Product Architecture, in the PDMA," in Handbook of New Product Development, M. R. Jr., Ed. Wiley \& Sons, 1996.

[9] W. G. Rodenacker and J. Schäfer, "Methodisches Konstruieren einer Anlage zur Herstellung von Atemkalk," Chemie Ing. Tech., vol. 50, no. 9, pp. 669-673, 1978.

[10] K. Roth, Konstruieren mit Konstruktionskatalogen. Berlin, Heidelberg: Springer Berlin Heidelberg, 1982.

[11] R. Koller, Konstruktionslehre für den Maschinenbau. Berlin, Heidelberg: Springer Berlin Heidelberg, 1985.

[12] A. Little, K. L. Wood, and D. A. McAdams, "Functional analysis: A fundamental empirical study for reverse engineering, benchmarking and redesign," in ASME DETC, 1997.

[13] S. Szykman, J. W. Racz, and R. D. Sriram, "The Representation of Function in ComputerBased Design," in International conference on design theory and methodology, 1999, pp. 233246.

[14] R. B. Stone and K. L. Wood, "Development of a functional basis for design," J. Mech. Des. Trans. ASME, vol. 122, no. 4, pp. 359-370, 2000.

[15] J. Hirtz, R. B. Stone, D. A. McAdams, S. Szykman, and K. L. Wood, "A functional basis for engineering design: Reconciling and evolving previous efforts," Res. Eng. Des. - Theory, Appl. Concurr. Eng., vol. 13, no. 2, pp. 65-82, 2002.

[16] Y. Umeda, M. Ishii, M. Yoshioka, Y. Shimomura, and T. Tomiyama, "Supporting conceptual design based on the function-behavior-state modeler," Artif. Intell. Eng. Des. Anal. Manuf., vol. 10, no. 4, pp. 275-288, 1996.

[17] Y. Shimomura, M. Yoshioka, H. Takeda, Y. Umeda, and T. Tomiyama, "Representation of design object based on the functional evolution process model," J. Mech. Des. Trans. ASME, vol. 120, no. 2, pp. 221-229, 1998. 
[18] J. S. Gero, "1990-Function,Behaviour,and Structure.pdf," AI Mag., vol. 11, no. 4, pp. 26-36, 1990.

[19] J. S. Gero and U. Kannengiesser, "The situated function-behaviour-structure framework," Des. Stud., vol. 25, no. 4, pp. 373-391, Jul. 2004.

[20] W. Y. Y. Zhang, S. B. Tor, G. A. A. Britton, and Y. M. M. Deng, "Functional design of mechanical products based on behavior-driven function-environment-structure modeling framework," in Innovation in Manufacturing Systems and Technology (IMST), 2002, no. December 2003.

[21] A. J. Robotham, "The use of function/means trees for modelling technical, semantic and business functions," J. Eng. Des., vol. 13, no. 3, pp. 243-251, Sep. 2002.

[22] V. H. Y. Lo, P. Humphreys, and D. Sculli, "The definition method zero applied to ISO 9000 quality manuals," TQM Mag., vol. 13, no. 2, pp. 105-111, Apr. 2001.

[23] Y. Kitamura and R. Mizoguchi, "Ontology-based systematization of functional knowledge," $J$. Eng. Des., vol. 15, no. 4, pp. 327-351, 2004.

[24] W. E. Klein and V. R. Lalli, Model OA Wind Turbine Generator FMEA. Cleveland, Ohio, USA: NASA Glenn Research Center, 1989.

[25] M. Rausand and K. Oien, "The basic concepts of failure analysis," Reliab. Eng. Syst. Saf., vol. 58, pp. 73-83, 1996.

[26] W. S. Lee, D. L. Grosh, F. A. Tillman, and C. H. Lie, "Fault tree analysis, methods, and applications - a review," IEEE Trans. Reliab., vol. 34, no. 3, pp. 194-203, 1985.

[27] Y. Kitamura, M. Kashiwase, M. Fuse, and R. Mizoguchi, "Deployment of ontological framework of functional design knowledge," Adv. Eng. Informatics, vol. 18, no. 2, pp. 115$127,2004$.

[28] Y. Kitamura and R. Mizoguchi, "Ontology-based description of functional design knowledge and its use in a functional way server," Expert Syst. Appl., vol. 24, pp. 153-166, 2003.

[29] M. S. Erden, H. Komoto, T. J. Van Beek, V. D’Amelio, E. Echavarria, and T. Tomiyama, “A review of function modeling: Approaches and applications," Artif. Intell. Eng. Des. Anal. Manuf. AIEDAM, vol. 22, no. 2, pp. 147-169, 2008.

[30] J. De Kleer and J. S. Brown, "Qualitative Physics based on Confluences," Artif. Intell., vol. 24, no. 1, pp. 7-83, 1984.

[31] K. D. Forbus, “Qualitative Process Theory,” Artif. Intell., vol. 24, no. 1, pp. 85-168, 1984.

[32] B. Chandrasekaran and J. R. Josephson, "Function in Device Representation," Eng. Comput., vol. 16, no. 3-4, pp. 162-177, Dec. 2000.

[33] Y. Umeda and T. Tomiyama, "FBS modeling: modeling scheme of function for conceptual design," in Proc. Working Papers of the 9th Int. Workshop on Qualitative Reasoning About Physical Systems, 1995, pp. 271-278.

[34] M. Yoshioka, Y. Umeda, H. Takeda, Y. Shimomura, Y. Nomaguchi, and T. Tomiyama, "Physical concept ontology for the knowledge intensive engineering framework," Adv. Eng. Informatics, vol. 18, no. 2, pp. 95-113, 2004.

[35] A. M. Keuneke, "Device Representation - The Significance of Functional Knowledge," IEEE 
Expert, vol. 6, no. 2, pp. 22-25, 1991.

[36] Y. M. Deng, S. B. Tor, and G. A. Britton, "Abstracting and exploring functional design information for conceptual mechanical product design," Eng. Comput., vol. 16, no. 1, pp. 3652,2000 .

[37] M. Balachandran and J. S. Gero, "Role of prototypes in integrated expert systems and CAD systems," in Applications of Artificial Intelligence in Engineering V, 1990, pp. 195-211.

[38] W. G. Rodenacker, Methodisches Konstruieren. Berlin, Germany: Springer-Verlag, 1971.

[39] R. V Welch and J. R. Dixon, "Representing function, behavior and structure during conceptual design," in Design Theory and Methodology - DTM'92, 1992, pp. 11-18.

[40] R. H. Bracewell and J. E. E. Sharpe, "Functional descriptions used in computer support for qualitative scheme generation-'Schemebuilder," Artif. Intell. Eng. Des. Anal. Manuf., vol. 10, no. 4, pp. 333-345, Sep. 1996.

[41] R. Rosenberg and D. C. Karnopp, Introduction to Physical System Dynamics. New York, USA: McGraw-Hill, 1983.

[42] S. Ahmed and K. Wallace, "Evaluating a Functional Basis," in ASME Internationa Design Engineering Technical Conference IDETC 2003, 2003.

[43] J. S. Gero, "Design Prototypes: A Knowledge Representation Schema for Design," AI Magazine, 1990.

[44] Y. M. Deng, "Function and behavior representation in conceptual mechanical design," Artif. Intell. Eng. Des. Anal. Manuf., vol. 16, no. 5, pp. 343-362, 2002.

[45] Y. M. Deng, G. A. Britton, and S. B. Tor, "Constraint-Based Functional Design Verification for Conceptual Design," Comput. Des., vol. 32, pp. 889-899, 2000.

[46] Y. M. Deng, S. B. Tor, and G. A. Britton, "A Computerized Design Environment for Functional Modeling of Mechanical Products," in Proceedings of 5th ACM Symposium on Solid Modelling, 1999, pp. 1-12.

[47] S. B. Tor, Y. M. Deng, and G. A. Britton, "A Comprehensive Representation Model for Functional Design of Mechanical Products," in Proceedings of 12th International Conference on Engineering Design, 1999, pp. 1929-1932.

[48] S. Borgo, M. Carrara, P. Garbacz, and P. E. Vermaas, "A Formal Ontological Perspective on the behaviors and Functions of Technical Artifcats," Artif. Intell. Eng. Des. Anal. Manuf., vol. 23, no. 1, pp. 3-21, 2009.

[49] H. Komoto and T. Tomiyama, "A Theory of Decomposition in System Architecting," in Proceedings of the 18th international Conference on Engineering Design (ICED11), 2011.

[50] J. Pailhès, M. Sallaou, J. P. Nadeau, and G. M. Fadel, "Energy based functional decomposition in preliminary design," J. Mech. Des. Trans. ASME, vol. 133, no. 5, pp. 1-10, 2011.

[51] D. Russo and T. Montecchi, "Creativity Techniques for Computer Aided Inventing System," in Proceedings of the 18th international Conference on Engineering Design (ICED11), 2011.

[52] D. Russo and T. Montecchi, "A Function-Behavior Oriented Search for Patent Digging," in ASME 2011 International Design Engineering Technical Conferences and Computers and Information in Engineering Conference, 2011, pp. 1111-1120. 
[53] A. Chakrabarti, "SAPPhIRE - An Approach to Analysis and Synthesis," in Proceedings of ICED 09, the 17th International Conference on Engineering Design, 2009.

[54] G. Cascini, D. Russo, and M. Zini, "Computer-Aided Patent Analysis: Finding Invention Peculiarities," in Trends in Computer-Aided Innovation, 2007, pp. 167-178.

[55] G. Fantoni, R. Apreda, F. Dell'Orletta, and M. Monge, "Automatic Extraction of FunctionBehavior-State Information from Patents," Adv. Eng. Informatics, vol. 27, no. 3, pp. 317-334, 2013.

[56] D. C. Brown, "Functional, Behavioral and Structural Features," in ASME 2003 International Design Engineering Technical Conferences and Information in Engineering Conference, 2003, pp. 895-900.

[57] Y. Umeda, H. Takeda, T. Tomiyama, and H. Yoshikawa, "Function, Behaviour and Structure," in Artificial Intelligence in Engineering, 1990.

[58] A. K. Goel, "Integration of case-based reasoning and model-based reasoning for adaptive design problem solving," Ohio State University, 1989.

[59] A. K. Goel, "Representation of design functions in experience-based design," in Intelligent Computer Aided Design, 1992, pp. 283-308.

[60] A. K. Goel, S. R. Bhatta, and E. Stroulia, "Kritik: an early case-based design system," in Issues and Applications of Case-Based Reasoning in Design, 1997, pp. 87-132.

[61] A. K. Goel and S. R. Bhatta, "Use of design patterns in analogy-based design," Adv. Eng. Informatics, vol. 18, pp. 85-94, 2004.

[62] R. V Welch and J. R. Dixon, "Guiding Conceptual Design Through Behavioral Reasoning," Res. Eng. Des., vol. 6, pp. 169-188, 1994.

[63] N. Snooke and C. Price, "Hierarchical functional reasoning," Knowledge-Based Syst., vol. 11, pp. 301-309, 1998.

[64] B. Chandrasekaran, "Functional Representation: A Brief Historical Perspective," Appl. Artif. Intell., vol. 8, no. 2, pp. 173-197, Apr. 1994.

[65] B. Chandrasekaran, "Functional Representation and Causal Processes," 1994, pp. 73-143.

[66] B. H. Far and A. H. Elamy, "Functional reasoning theories: Problems and perspectives," Artif. Intell. Eng. Des. Anal. Manuf. AIEDAM, vol. 19, no. 2, pp. 75-88, 2006.

[67] B. Chandrasekaran, "Representing function: Relating functional representation and functional modeling research streams," Artif. Intell. Eng. Des. Anal. Manuf., vol. 19, no. 02, pp. 65-74, May 2005.

[68] P. America and J. van Wijgerden, "Requirements Modeling for Families of Complex Systems," in Workshop on Software Architecture for ProductFamilies, Lecture Notes in Computer Science, Berlin, Germany: Springer, 2000, pp. 199-209.

[69] G. Maarten Bonnema and F. J. A. M. van Houten, "Use of models in conceptual design," J. Eng. Des., vol. 17, no. 6, pp. 549-562, 2006.

[70] G. Pahl and W. Beitz, Engineering Design - A Systematic Approach, First Engl. London / Berlin: The Design Council / Springer, 1984.

[71] R. L. Nagel, K. L. Perry, R. B. Stone, and D. A. McAdams, "Functioncad: A functional 
modeling application based on the function design framework," in Proceedings of the ASME Design Engineering Technical Conference, 2009, vol. 2, no. PARTS A AND B, pp. 591-600.

[72] C. Sen, J. D. Summers, and G. M. Mocko, "A Protocol to Formalise Function Verbs to Support Conservation-based Model Checking," J. Eng. Des., vol. 22, no. 11-12, pp. 765-788, 2011.

[73] L. Yuan, Y. Liu, Z. Sun, Y. Cao, and A. Qamar, "A hybrid approach for the automation of functional decomposition in conceptual design," J. Eng. Des., vol. 27, no. 4-6, pp. 333-360, 2016.

[74] K. Gericke and B. Eisenbart, "The integrated function modeling framework and its relation to function structures," Artif. Intell. Eng. Des. Anal. Manuf. AIEDAM, vol. 31, no. 4, pp. 436-457, 2017.

[75] A. Chakrabarti, L. Siddharth, M. Dinakar, M. Panda, N. Palegar, and S. Keshwani, "Idea Inspire 3.0-A Tool for Analogical Design," 2017, pp. 475-485.

[76] D. A. McAdams, R. B. Stone, and K. L. Wood, "Functional Interdependence and Product Similarity Based on Customer Needs," Res. Eng. Des., vol. 11, no. 1, pp. 1-19, Apr. 1999.

[77] M. A. Kurfman, R. B. Stone, M. VanWie, K. L. Wood, and K. N. Otto, "Theoretical underpinnings of functional modeling: preliminary experimental studies," 12th International Conference on Design Theory and Methodology, no. September. 2000.

[78] C. R. Bryant, R. B. Stone, D. A. McAdams, and T. Kurtoglu, "Concept generation from the functional basis of design," in International conference on enngineering design, 2005, pp. 139160.

[79] P. SRIDHARAN and M. I. CAMPBELL, "A study on the grammatical construction of function structures," Artif. Intell. Eng. Des. Anal. Manuf., vol. 19, no. 3, pp. 139-160, Aug. 2005.

[80] B. W. Caldwell, C. Sen, G. M. Mocko, J. D. Summers, and G. M. Fadel, "Empirical examination of the functional basis and design repository," Des. Comput. Cogn. '08 - Proc. 3rd Int. Conf. Des. Comput. Cogn., no. January, pp. 261-280, 2008.

[81] J. Schultz, C. Sen, B. Caldwell, J. Mathieson, J. D. Summers, and G. M. Mocko, "Limitations to Function Structures: A Case Study in Morphing Airfoil Design," in Volume 5: 22nd International Conference on Design Theory and Methodology; Special Conference on Mechanical Vibration and Noise, 2010, pp. 405-417.

[82] B. W. Caldwell, J. E. Thomas, C. Sen, G. M. Mocko, and J. D. Summers, "The Effects of Language and Pruning on Function Structure Interpretability," J. Mech. Des., vol. 134, no. 6, Jun. 2012.

[83] C. Sen and J. D. Summers, "A Pilot Protocol Study on How Designers Construct Function Structures in Novel Design," in Design Computing and Cognition '12, Dordrecht: Springer Netherlands, 2014, pp. 247-264.

[84] R. L. Nagel and D. Ph, "An Investigation Into the Effectiveness of an Algorithmic," Proc. ASME 2013 Int. Des. Eng. Tech. Conf. Comput. Inf. Eng. Conf., pp. 1-17, 2013.

[85] T. Tomiyama, T. J. Van Beek, A. A. A. Cabrera, H. Komoto, and V. D’Amelio, "Making function modeling practically usable," Artif. Intell. Eng. Des. Anal. Manuf. AIEDAM, vol. 27, no. 3, pp. 301-309, 2013.

[86] B. Eisenbart, K. Gericke, L. T. M. Blessing, and T. C. McAloone, "A DSM-based framework for integrated function modelling: concept, application and evaluation," Res. Eng. Des., vol. 28, 
no. 1, pp. 25-51, Jan. 2017.

[87] A. S. Gill, J. D. Summers, and C. J. Turner, "Comparing function structures and pruned function structures for market price prediction: An approach to benchmarking representation inferencing value," Artif. Intell. Eng. Des. Anal. Manuf., vol. 31, no. 4, pp. 550-566, Nov. 2017.

[88] H. Mokhtarian, E. Coatanéa, and H. Paris, "Function modeling combined with physics-based reasoning for assessing design options and supporting innovative ideation," Artif. Intell. Eng. Des. Anal. Manuf. AIEDAM, vol. 31, no. 4, pp. 476-500, 2017.

[89] A. Thiagarajan, A. Patel, S. O'Shields, and J. D. Summers, "Functional Thinking: A Protocol Study to Map Modeling Behavior of Designers," in Design Computing and Cognition '16, Cham: Springer International Publishing, 2017, pp. 339-357.

[90] Q. Wang, J. Y. Zhu, Y. Q. Shu, M. Rao, and K. T. Chuang, "An Intelligent design environment for conceptual process design,” Eng. Appl. Artif. Intell., vol. 8, no. 2, pp. 115-127, 1995.

[91] T. Kersten, “"Modessa', A Computer Based Conceptual Design Support System,” in AI System Support for Conceptual Design, London: Springer London, 1996, pp. 241-259.

[92] G. Q. Huang, "Web-based morphological charts for concept design in collaborative product development," J. Intell. Manuf., vol. 10, no. 3-4, pp. 267-278, 1999.

[93] D. Rentema, F. Jansen, and E. Torenbeek, "The application of AI and geometric modelling techniques in conceptual aircraft design," in 7th AIAA/USAF/NASA/ISSMO Symposium on Multidisciplinary Analysis and Optimization, 1998.

[94] D. Rentema, "AIDA: Artificial Intelligence supported conceptual Design of Aircraft," Technische Universiteit Delft, 2004.

[95] W. Y. Zhang, S. B. Tor, G. A. Britton, and Y. M. Deng, "EFDEX: A knowledge-based expert system for functional design of engineering systems," Eng. Comput., vol. 17, no. 4, pp. 339353, 2001.

[96] N. Vargas-Hernandez and J. J. Shah, "2nd-CAD: A Tool for Conceptual Systems Design in Electromechanical Domain,” J. Comput. Inf. Sci. Eng., vol. 4, no. 1, pp. 28-36, Mar. 2004.

[97] A. Chakrabarti, P. Sarkar, B. Leelavathamma, and B. S. Nataraju, "A functional representation for aiding biomimetic and artificial inspiration of new ideas," AI EDAM, vol. 19, no. 02, May 2005.

[98] C. Bryant, D. A. McAdams, and R. B. Stone, "A computational technique for concept generation - DETC2005-85323," ASME Int. Des. Eng. Tech. Conf. IDETC 2005, no. January, 2005.

[99] C. R. Bryant Arnold, R. B. Stone, and D. A. McAdams, "Memic: An interactive morphological matrix tool for automated concept generation," IIE Annu. Conf. Expo 2008, pp. 1196-1201, 2008 .

[100] D. Engida Woldemichael and F. Mohd Hashim, "A framework for function $\square$ based conceptual design support system,” J. Eng. Des. Technol., vol. 9, no. 3, pp. 250-272, 2011.

[101] M. R. Bohm, R. L. Nagel, and M. K. Riggs, "Utilizing design intent information to aid in the synthesis of multi-domain systems," Comput. Aided. Des. Appl., vol. 14, no. 1, pp. 17-27, 2017. 